\title{
EDITORIAL
}

\section{Toward a developmental perspective on conduct disorder}

\author{
JOHN E. RICHTERS ${ }^{a}$ AND DANTE CICCHETTI ${ }^{b}$ \\ ${ }^{\circ}$ Child and Adolescent Disorders Research Branch, National Institute of Mental \\ Health; and ${ }^{b} M t$. Hope Family Center, University of Rochester
}

If a man have a stubborn and rebellious son, that will not hearken unto the voice of his father, or the voice of his mother, and though they chasten him, will not hearken unto them; then shall his father and his mother lay hold on him, and bring him unto the elders of the city, and unto the gates of this place; and they shall say unto the elders of this city; "This our son is stubborn and rebellious, he doth not hearken to our voice; he is a glutton and a drunkard." And all the elders of his city shall stone him with stones, that he die; so shall thou put away the evil from the midst of thee; and all of Israel shall hear and fear. (Deuteronomy, XXII: 18-22)

It would be difficult to exaggerate the pessimism that has always surrounded the topic of antisocial children. Although the source of this pessimism is easy enough to identify, its remedy has proven elusive. All societies

\footnotetext{
The opinions expressed here are those of the authors and do not necessarily represent the position of the National Institute of Mental Health. John Richters' work on this special issue was supported in part through funding from the John D. and Catherine T. MacArthur Foundation. Dante Cicchetti's work on this special issue was supported by a grant from the Prevention Research Branch of the National Institute of Mental Health (MH45027). We owe a special gratitude to Drs. Peter Jensen and Marian Radke-Yarrow for their encouragement and support on this project. We also thank the contributors to this special issue for their dedication and commitment to this project, and for their continuing contributions to the field. Requests for reprints may be sent to John Richters, Child and Adolescent Disorders Research Branch, NIMH, 5600 Fishers Lane, Room 10-104, Rockville, Maryland 20857.
}

rely on mutually reinforcing systems of mores, customs, laws, religion, and childrearing, to impart to each new generation widely shared standards for personal conduct and social commerce. Yet, despite these pressures, there are children in every generation who manage to emerge on the other side of the socialization net, somehow beyond the reach and influence of those systems. An all too common and predictable result, as psychiatrist Hervey Cleckley once noted, is the ". . . woe, confusion, despair, farce, and disaster" they leave in their social wakes as they progress from childhood to adulthood:

Turning now to penal facilities, now to psychiatric institutions, relatives, friends, doctors, or the community at large, all find themselves at a loss, almost as if they were trying to measure area in kilowatts, or color in inches. Since the fire extinguisher did not particularly help the child's fever, which has become alarming, we gravely decide to apply a plaster cast. There are no really appropriate remedies available. (Cleckley, 1964, p. 282)

The scientific community has been no less challenged by the problem of antisocial behavior in childhood. Indeed, for several decades now the topic has been a focus of research and thinking in an impressive array of scientific disciplines, including developmental psychology, child psychiatry, neuropsychology, psychobiology, epidemiology, criminology, and sociology (Wilson \& Herrnstein, 1985). As a consequence, we 
probably know more about the predictors, concurrent correlates, sequelae, and longitudinal course of antisocial behavior than we do for any other syndrome of childhood. But, despite this concentrated attention there is still little that we can say with confidence about how the accumulated facts should be interpreted, why antisocial trajectories develop, why they broaden and deepen with development in some children yet taper off in others, and why they are so difficult to deflect once stabilized. There are promising theories to be sure. But so far there has been little in the way of anything approaching consensus.

In part, this is attributable to the fact that the study of antisocial children is still in its infancy. Although the antisocial problem dates back probably thousands of years, it has been a focus of systematic study for only the past 50 years or so. But there is another reason, at once more subtle and powerful. It concerns the increasingly common, highly specialized nature of inquiry both within and across the scientific disciplines concerned with antisocial behavior.

The nature of specialized inquiry is such that neighboring disciplines and subdisciplines approach the phenomenon of antisocial behavior at different levels of analysis, ranging from physiological through psychological to sociological, each with different constructs, conceptual schemas, research strategies, and highly individualized languages. Although this degree of specialization is necessitated by the complexity of the processes and mechanisms under study, resulting knowledge gains tend to accumulate within disciplines, with little in the way of common language and concepts for integrating knowledge across disciplines. Moreover, specialization often brings with it the relatively isolated consideration of specific mechanisms, and only limited attention to the broader matrix of contexts and processes in which those mechanisms exert their influences. In a word, the study of childhood antisocial behavior has very much developed along multidisciplinary rather than interdisciplinary lines, absent the necessary theoretical and conceptual connective tissue for integrating knowledge across disciplines.

The impetus for this special issue of $D e$ velopment and Psychopathology lies in our conviction that the principles of developmental psychopathology provide a much needed conceptual scaffolding for the facilitation of this integration (Cicchetti, 1984; Cicchetti \& Richters, 1993 [this issue]; Cicchetti \& Toth, 1991). Its emphasis on the interplay between normal and abnormal development, continuity and discontinuity, and risk and protective factors, and on influences both within and outside the individual, transcends traditional disciplinary boundaries and provides fertile ground for moving beyond descriptive facts to a process level understanding of antisocial trajectories (Cicchetti \& Richters, 1993 [this issue]; Cicchetti \& Schneider-Rosen, 1986). Rather than competing with existing theories and foci, the developmental psychopathology perspective provides a broad, integrative framework within which the contributions of individual disciplines can be fully realized in the broader context of understanding individual functioning and development. Thus, its own contribution potential lies in the heuristic power it holds for transducing facts into knowledge and knowledge into understanding.

The integrative power of this perspective is reflected in the recent Institute of Medicine (IOM) (1989) report entitled Research on Children and Adolescents with Mental, Behavioral, and Developmental Disorders. The IOM report highlights the innovative contributions that a developmental framework could make in elucidating our understanding of the causes and determinants of the disorders of childhood and in discovering the relationship between normal development and disorder. As noted in the IOM report, the developmental psychopathology approach "takes into account the emerging behavioral repertoire, cognitive and language functions, social and emotional processes, and changes occurring in anatomical structures and physiological processes of the brain" (p. 14). In addition 
to its central role in influencing the thinking of the IOM report, the developmental psychopathology perspective played a prominent role in the development of the National Institute of Mental Health's National Plan for Research on Child and Adolescent Mental Disorders (National Advisory Mental Health Council, 1990).

The impetus for this special issue grew out of a workshop entitled Developmental Perspectives on Conduct Disorder in April 1992. The workshop, organized by John Richters and Dante Cicchetti and cosponsored by the John D. and Catherine T. MacArthur Foundation Early Childhood Transition Network and the National Institute of Mental Health, was conceptualized within a developmental psychopathology framework. This special issue is a distillate of the papers presented during, and the thought-provoking discussions generated at, the workshop.

In organizing this special issue, we had in mind two related objectives. First, we wanted the articles to reflect the current state of knowledge in the major substantive domains of research and theory concerning conduct disorder, but with one important caveat. Rather than merely reflecting the findings in those domains, we asked the contributors to employ a developmental perspective to highlight the strengths and limitations of our knowledge in each area and to suggest promising questions and strategies for subsequent research. If there is a single theme that emerges from each of the contributions in this issue, it is that no approach, construct, level of analysis, or research strategy alone is sufficient to address the complex, multidetermined phenomenon of antisocial behavior. Our second goal, therefore, was and is to kindle among researchers an appreciation of the value of approaching the study of childhood antisocial behavior within a developmental psychopathology framework.

It may have occurred to the reader that our juxtaposition of the terms developmental and conduct disorder in the title of this special issue amounts to an oxymoron. Not only is there nothing developmental about the diagnosis of conduct disorder, but also the resistance of its diagnostic criteria to contextual information about a child's developmental history, capacities, and circumstances might even be viewed as antidevelopmental (Richters \& Cicchetti, 1993 [this issue]). Moreover, disagreements over the medical model on which the conduct disorder diagnosis is based have long hindered collaborative research between clinical and developmental researchers, perpetuating gaps between the study of normal and abnormal development. Although these are often raised as legitimate criticisms of the conduct disorder diagnosis, we find them compelling reasons to draw the Diagnostic and Statistical Manual of Mental Disorders (DSM; American Psychiatric Association, 1987) and diagnoses such as conduct disorder into the mainstream of developmental psychopathology research.

In spite of the numerous scientific and philosophical issues that continue to plague the DSM system, it remains the common language used by mental health professionals and public health agencies to communicate about the problems and conditions for which the mental health community has professional responsibility (Wakefield, 1992; Wilson, 1993). Thus, linking our research to the common language of the DSM maximizes the likelihood that resulting knowledge will benefit the children who are the ultimate source of our concern. It is no small consideration that this in turn helps to ensure that our research will be valued and perceived as relevant to the public health and mental health communities, which have an increasingly powerful influence on research funding priorities.

While we believe that these are compelling reasons to link developmental psychopathology research to the DSM language, they are not arguments for allowing the DSM system to shape our research and thinking. On the contrary, the DSM language link should be harnessed as a means for developmental psychopathologists to influence the thinking and actions of those in the mental health community. Links between the DSM system and developmental 
psychopathology research hold considerable promise for challenging existing assumptions, and for refining the ways in which the mental health community conceptualizes, assesses, classifies, communicates about, and treats the adjustment problems and functioning impairments of childhood. Ultimately, it may be unrealistic to expect an administrative classification system such as the DSM - serving so many different and often conflicting constituencies - to be completely responsive to knowledge gains in a timely fashion (Schacht, 1985; Schacht \& Nathan, 1977). At some point it may even be necessary for developmental scientists to reconsider developing a classification system at once more faithful

\section{References}

American Psychiatric Association. (1987). Diagnostic and statistical manual of mental disorders (3rd ed., rev.). Washington, DC: Author.

Cicchetti, D. (1984). The emergence of developmental psychopathology. Child Development, 55, 1-7.

Cicchetti, D., \& Richters, J. E. (1993). Developmental considerations in the investigation of conduct disorder. Development and Psychopathology, 5, 331344.

Cicchetti, D., \& Schneider-Rosen, K. (1986). An organizational approach to childhood depression. In $M$. Rutter, C. E. Izard, \& P. B. Read (Eds.), Depression in young people: Developmental and clinical perspectives (pp. 71-134). New York: Guilford Press.

Cicchetti, D., \& Toth, S. L. (1991). The making of a developmental psychopathologist. In J. Cantor, C. Spiker, \& L. Lipsitt (Eds.), Child behavior and development: Training for diversity (pp. 34-72). Norwood, NJ: Ablex.

Cleckley, H. (1964). The mast of sanity (4th ed.). St. Louis, MO: C. V. Mosby Press.

Institute of Medicine. (1989). Research on children and adolescents with mental, behavioral, and de- to developmental principles and context and more responsive to the needs of the research community. In any event, we believe there will always be a compelling need to link our research with the common language of the mental health community.

Finally, we believe that this remarkable set of papers will serve as an important milestone in the history of research concerning antisocial children. The papers not only summarize and synthesize the impressive knowledge gains in each area within a developmental framework, but also provide a compelling research agenda for the future and a rationale for pursuing that agenda in a more coordinated, integrated, interdisciplinary fashion than has characterized progress in the past.

velopmental disorders. Washington, DC: National Academy Press.

National Advisory Mental Health Council. (1990). National plan for research on child and adolescent mental disorders. Rockville, MD: National Institute of Mental Health.

Richters, J. E., \& Cicchetti, D. (1993). Mark Twain meets DSM-III-R: Conduct disorder, development, and the concept of harmful dysfunction. Development and Psychopathology, 5, 5-29.

Schacht, T. E. (1985). DSM-III and the politics of truth. American Psychologist, 40, 515-521.

Schacht, T. E., \& Nathan, P. E. (1977). But is it good for psychologists? Appraisal and status of DSMIII. American Psychologist, 32, 1017-1025.

Wakefield, J. C. (1992). The concept of mental disorder: On the boundary between biological facts and social values. American Psychologist, 47, 373-388.

Wilson, M. (1993). DSM-III and the transformation of American psychiatry, American Journal of Psychiatry, 150, 399-410.

Wilson, J. Q., \& Herrnstein, R. J. (1985). Crime and human nature. New York: Simon \& Schuster. 